University of Wollongong

Research Online

Faculty of Social Sciences - Papers (Archive) Faculty of Arts, Social Sciences \& Humanities

$1-1-2018$

\title{
What is the impact of professional learning on physical activity interventions among preschool children? A systematic review
}

\author{
Michele Peden \\ University of Wollongong, mep948@uowmail.edu.au \\ Anthony D. Okely \\ University of Wollongong, tokely@uow.edu.au \\ Michelle J. Eady \\ University of Wollongong, meady@uow.edu.au \\ Rachel A. Jones \\ University of Wollongong, rachelj@uow.edu.au
}

Follow this and additional works at: https://ro.uow.edu.au/sspapers

Part of the Education Commons, and the Social and Behavioral Sciences Commons

Research Online is the open access institutional repository for the University of Wollongong. For further information contact the UOW Library: research-pubs@uow.edu.au 


\title{
What is the impact of professional learning on physical activity interventions among preschool children? A systematic review
}

\begin{abstract}
The purpose of this systematic review was to investigate professional learning models (length, mode, content) offered as part of objectively measured physical childcare-based interventions. A systematic review of eight electronic databases was conducted to June 2017. Only English, peer-reviewed studies that evaluated childcare-based physical activity interventions, incorporated professional learning and reported objectively measured physical activity were included. Study designs included randomized controlled trails, cluster randomized trials, experimental or pilot studies. The search identified 11 studies. Ten studies objectively measured physical activity using accelerometers; five studies used both accelerometer and direct observation tools and one study measured physical activity using direct observation only. Seven of these studies reported statistically significant intervention effects. Only six studies described all components of professional learning, but only two studies reported specific professional learning outcomes and physical activity outcomes. No patterns were identified between the length, mode and content of professional learning and children's physical activity outcomes in childcare settings. Educators play a critical role in modifying children's levels of physical activity in childcare settings. The findings of this review suggest that professional learning offered as part of a physical activity intervention that potentially impacts on children's physical activity outcomes remains underreported.
\end{abstract}

\section{Keywords}

among, interventions, activity, physical, learning, professional, review, impact, systematic, children?, preschool

\section{Disciplines}

Education | Social and Behavioral Sciences

\section{Publication Details}

Peden, M. E., Okely, A. D., Eady, M. J. \& Jones, R. A. (2018). What is the impact of professional learning on physical activity interventions among preschool children? A systematic review. Clinical Obesity, 8 (4), 285-299. 


\title{
What is the impact of professional learning on physical activity interventions among preschool children? A systematic review
}

Michele E. Peden ${ }^{\mathrm{a}, \mathrm{b}}$, Anthony D. Okely ${ }^{\mathrm{a}, \mathrm{b}, \mathrm{c}}$, Michelle J. Eady ${ }^{\mathrm{b}}$, Rachel A. Jones ${ }^{\mathrm{a}, \mathrm{b}, \mathrm{c}}$ Affiliations: ${ }^{a}$ Early Start, School of Education, Faculty of Social Sciences, University

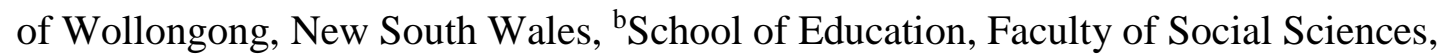
University of Wollongong, Australia, ${ }^{\mathrm{c}}$ Illawarra Health and Medical Research Institute, University of Wollongong, Australia.

PROSPERO 2016: CRD42016032941. Available from: http://www.crd.york.ac.uk/PROSPERO

Keywords: professional learning, physical activity, children, intervention

\begin{abstract}
Objective: The purpose of this systematic review was to investigate professional learning models (length, mode, content) offered as part of objectively measured physical childcare-based interventions.
\end{abstract}

Methods: A systematic review of 8 electronic databases was conducted to June 2017. Only English, peer-reviewed studies that evaluated childcare-based physical activity interventions, incorporated professional learning and reported objectively measured physical activity were included. Study designs included randomised controlled trails, cluster randomised trials, experimental or pilot studies.

Results: The search identified eleven studies. Ten studies objectively measured physical activity using accelerometers; five studies used both accelerometer and direct observation tools and one study measured physical activity using direct observation only. Seven of these studies reported statistically significant intervention effects. Only six studies described all components of professional learning, but only two studies 
reported specific professional learning outcomes and physical activity outcomes. No patterns were identified between the length, mode and content of professional learning and children's physical activity outcomes in childcare settings.

Conclusions: Educators play a critical role in modifying children's levels of physical activity in childcare settings. The findings of this review suggest that professional learning offered as part of a physical activity intervention that potentially impacts on children's physical activity outcomes remains under-reported.

\section{Abbreviations:}

PICO (Population, Intervention, Intervention/exposure, Comparator/control, and

\section{Outcome)}

Evaluation Policy Assessment Observation (EPAO)

Observational System for Recording Physical Activity in Children- Preschool (OSRAC-P).

Light Physical Activity (LPA)

Moderate-to-Vigorous-intensity Physical Activity (MVPA)

Moderate-intensity Physical Activity (MPA)

Vigorous-intensity Physical Activity (VPA)

\section{What is already known about this subject?}

- Physical activity intervention facilitated in early childhood education and care setting are relatively successful 
- Physical activity intervention facilitated in early childhood education and care settings are diverse in length, duration and approach.

- Key components that result such interventions remain unresolved.

Professional learning for educators may be important in successful physical activity interventions

\section{What does this study add?}

- No studies have identified potential patterns between professional learning and children's objectively measured physical activity in early childhood education and care settings following implementation of physical activity interventions.

- Additional information detailing professional learning content, mode and length is needed.

- Professional learning is important within early childhood education and care sector. Alternate delivery options, such as blended or multi-mode professional models need to be considered. 


\section{Introduction}

Childhood obesity is an international public health problem (1), with low levels of physical activity potentially being a contributory factor to excess weight gain in young children (2). The early years (ages 0-5) is a significant developmental period, during which healthy behaviours, such as physical activity are established (3). Regular physical activity is associated with more favourable health outcomes, such as improved cardiovascular health, bone density, concentration, obesity prevention and psychological well-being $(4,5)$. Current physical activity guidelines recommend that toddlers and preschoolers' (ages 2-5) should accumulate at least three hours of physical activity per day $(6,7,8)$ for optimal health. Furthermore, the Institute of Medicine (USA) recommends that obesity prevention interventions should begin targeting children under the age of five and suggests that children should be active for 15 minutes per hour whilst in formal care (9). Unfortunately, a suboptimal percent of young children participate in sufficient physical activity $(10,11,12)$. 
With a high proportion of children attending formal child care, these settings have been highlighted as an ideal environment to promote physical activity (and in turn prevent overweight and obesity) $(13,14,15)$. Physical activity interventions facilitated within early childhood education and care settings, that didn't specifically target overweight or non-overweight children, have generally been well received by educators and children (16), however, changes in physical activity outcomes have been varied $(17,18,19,20,21,22,23)$.

The key components of success for physical activity interventions in early childhood education and care settings remain largely unresolved with many interventions comprising of multiple components. Past reviews have reported that intervention designs that support both educators and parents in increasing physical activity engagement levels and health outcomes for young children were key components in positively influencing changes in children's physical activity behaviours in child care settings $(20,24)$. Other key factors include availability of play equipment $(25,26)$, educator-led physical activity interventions (i.e. educators acting as an interventionist) or educator led structured physical activity lessons $(27,28)$, the role of the educators (29), and professional learning for the educators $(21,30,22)$. Other external factors may include age of children, socio economic status and parental influences (such as maternal physical activity levels $(31,32,33)$.

A number of physical activity interventions facilitated in early childhood education and care settings have included a professional learning component $(34,35,36)$, however the delivery length, length and intensity of professional learning varies greatly between studies. For example, some provide professional learning for 
educators in one-off sessions (37), while others offer professional learning over multiple sessions $(21,38)$. To date, it remains unknown if there are any potential patterns between the length, mode and content of professional learning provided to educators as part of a physical activity intervention and physical activity outcomes. Therefore, the following review aims to investigate the presence of potential patterns between professional learning and children's objectively measured physical activity in early childhood education and care settings.

\section{Methods}

\section{Protocol and registration}

The protocol for this systematic review was registered with PROSPERO international prospective register of systematic reviews (registering number CRD42016032941) and adheres to guidelines outlined in the Preferred Reporting items for systematic reviews and meta-analysis (PRISMA) statement (39).

\section{Inclusion and exclusion criteria}

The search was limited to original, full-text, peer-reviewed journal articles that were published in English. Whilst this article adheres to the PRISMA statement, it has been presented as PICO (40). Using the PICO (population, intervention, intervention/exposure, comparator/control, and outcome) format (40) the inclusion criteria are described below. 
Population: The two population groups included children aged 0-5 years enrolled in licenced public or commercial early childhood and care settings (preschool, nursery, long day care centres) and educators employed in these settings.

Intervention (exposure): All studies were randomised controlled trials, cluster randomised trials, or pilot studies that incorporated some professional learning (online, face-to-face, on-site visits or blended) which focused on increasing children's physical activity.

Comparator: All studies included a control group.

Outcomes (indicators): All studies reported objectively measured physical activity using a validated measurement tool such as accelerometers or observational tools including Evaluation Policy Assessment Observation (EPAO), Observational System for Recording Physical Activity in Children- Preschool (OSRAC-P).

Studies were excluded if they involved primary/secondary-aged children (6 years and older); children that attended out of school care programs (5 years and older) or family day care settings; special population groups (children with diagnosed conditions) and interventions that reported proxy reported physical activity.

\section{Study identification}

A computer-based literature search was conducted from September to June 2017. The search was carried out in eight databases; A+ Education, Education Research Complete, ERIC, ProQuest Central, Scopus, MEDLINE, SportDiscuss, PsycINFO and Web of Science. The following search string was used ("physical activit*" OR “gross motor" OR “movement” or "exercise”) AND ("preschool” OR "pre-school” 
OR "early childhood" OR “child care" OR “childcare") AND intervention AND (“training” OR “professional learning” OR “professional development” OR “staff development”). Additional studies were manually identified from references lists of included studies. The combined search hits from all databases were downloaded and entered in Endnote software reference management software (Endnote x7) and duplicates were removed.

\section{Study selection}

Studies were initially screened based on titles (MEP and RAJ). Included abstracts were then reviewed (MEP and RAJ). Full text versions were obtained and two reviewers independently assessed the full text (MEP and RAJ). Any discrepancies were resolved by further discussed until a consensus was reached.

\section{Data collection process}

Between January and June 2017, all data extraction was conducted by one author (MEP) and checked by another author for accuracy (RAJ). A standardised data extraction spread sheet was used to extract data on methodological variables in alignment with inclusion criteria. Extracted information included: characteristics of participants (age of children, number of children enrolled in setting), study design and duration, description of intervention (length, facilitator, follow-up), theoretical framework, primary and secondary outcomes, physical activity measures and outcomes, professional learning component (length, content, number of educators, incentives) and behavioural change techniques (goal setting, parental involvement). 
Quality Assessment

The Cochrane Collaboration's assessment tool was used to assess the quality and risk of the included studies. Items assessed included: (a) random sequence generation, (b) allocation of concealment, (c) blinding of participants and personnel, (d) blinding of outcomes assessment, (e) incomplete data, (f) selective reporting and (g) other reporting. Each item was assessed by three assessors (MEP, RAJ, MJE) as low risk, high risk or unclear. Any discrepancies were resolved via discussions and reexamination of individual articles with consensus reached.

\section{Results}

Study selection

The initial review resulted in the identification of 4247 studies. Thirty-seven full text articles were assessed and 11 studies were included in this review (Figure 1).

\section{Study Characteristics}

Table 2 summarises the study characteristics. Ten studies were randomised controlled trials $(34,41,42,37,43,35,44,36,45,27)$. Three studies were informed by socioecological theoretical theories $(44,35,43)$, whilst one study based their intervention on self-efficacy theory, (41) and three interventions were underpinned by social cognitive theory $(41,27,42)$. One study was guided by both social cognitive theory 
and self-determination theory (42). All studies were conducted between 2008 and 2016.

More than half the studies (58\%) were conducted in the USA $(\mathrm{N}=7)$

$(34,41,46,42,36,45,37)$ with the remaining studies conducted in Australia $(45,27)$, United Kingdom (44) and Switzerland (43). The length of the interventions varied from 8 weeks (41) to 2 years (35), averaging 26.5 weeks.

\section{Professional learning}

The length, mode and content of the professional learning were considered important for this review and were different between studies. Six of the eleven studies described all three of these components $(41,43,46,36,27,37)$. The length of the professional learning sessions varied. Three studies provided a single professional learning session $(41,46,37)$ and eight studies provided multiple professional learning sessions $(34,43,42,36,45,27,44,35)$. The majority of professional learning models that offered multiple sessions incorporated alternate modes of professional learning sessions such as booster sessions $(36,45)$, refresher training (34), group meetings (44), and ongoing on-site support $(36,42)$. The face-to-face professional learning sessions ranged from $2 \times 90$ minutes to $6 \times 60$ minutes.

One study described the quantity of professional learning sessions (five workshops), however no length of time for each session was discussed (43). The number of educators involved in the professional learning sessions were not described for any 
study, however one study reported 'all teachers' attended training, yet no figures of attendance were provided (46).

Nine studies reported the mode of the professional learning $(41,43,46,42,36,45,27,44,37)$ with face-to-face delivery the most frequently documented mode of delivery. Three studies used this mode exclusively $(38,42,27)$, while other studies supplemented the initial face-to-face workshops with onsite visits $(42,36)$, supplementary demonstration videos (provided independently from the faceto-face visits) $(27,37)$, and written materials/manuals $(46,36,27)$. Five studies provided financial based incentives for educators to participate in the intervention ranging from US\$5 to completed assigned homework (42) to CHF1500 (Swiss Franc) for services to rearrange their child care centres indoor and outdoor learning environments (43).

Only six studies reported aspects of educator training content (i.e. specific lesson content to be implemented in centres by educators, underlying themes of intervention, recommended pedagogy to be used, practical activities) $(41,43,46,36,27,37)$. For example, Bonvin et al 2013 focused on the relevant theories and practical implications of how to promote motor development and physical activity in early childhood education and care settings and resources showing how educators could implement the program (43). Similarly, Jones et al 2011 focused on how to implement structured and unstructured lessons to promote movement skill development, inclusive of both theory and practical components (45). Only two studies reported specific professional learning outcomes such as educator's motivational levels (43) and completion of ongoing tasks (i.e. educator lesson plans) (42). 
Physical activity outcomes

Five studies measured physical activity using accelerometers only $(41,42,36,44,35)$, five studies measured physical activity using accelerometers and direct observation $(34,43,45,27,37)$ and one study measured physical activity using direct observation only (46). Although all studies reported objective physical activity, several studies reported additional outcomes such as changes in child care environments (36), gross motor skill competence $(43,27,44)$ and body mass index $(42)$. All studies recorded physical activity within early childhood education and care hours only.

Different accelerometer epochs were used. O’Dwyer et al used 5s epochs (44) while others used 15 s epochs $(34,41,43,42,36,27,35,37)$. Cut points and wear time also differed. Four studies adopted Pate et al 2006 (47) cut points $(43,42,27,35)$ and four studies applied Sirard et al 2005 (48) cut points (34,45,44,37). Goldfield et al 2016 used Adolph et al (2012) (49) and Pfeiffer et al (2006) (50) cut points to allow for different intensities of physical activity with preschool children (36). Annessi et al 2013 cited numerous cut points $(47,51,48)$ to classify physical activity into various levels of intensity and De Marco et al reported no cut points (46). Wear time ranged from 1 day (43) to 20 days (37).

Of the 11 studies included in this review, seven studies reported significant changes in objectively measured physical activity post intervention $(34,41,42,36,44,35,37)$ (Table 2). In the Alhassen et al study, significant changes in light-intensity physical activity (LPA) $(\rho<.01)$ and moderate-to-vigorous-intensity physical activity (MVPA) 
$(\rho<.01)$ were reported (34). Annessi et al reported a significant change in MVPA and vigorous-intensity physical activity (VPA) $(\rho<.01)$ for both, equating to an $8.7 \%$ and 9.3\% increase respectively (41). Fitzgibbon et al 2011, reported significant changes in MVPA, moderate-intensity physical activity (MPA) and VPA $(\rho<.02, \rho<.05, \rho<.03$, respectively) for the intervention group compared to the control group (42). Goldfield et al reported significant differences between the intervention group and the control group for total physical activity $(\rho<.01)(36)$. Increases between groups for LPA were also reported, although differences were not significant. Pate et al reported significant differences in MVPA during preschool day $(\rho<.002)$ between the intervention group and the control group (35).

\section{Risk of bias}

Table 2 reports the risk of bias for each study. The majority (83\%) of studies reported unclear allocation concealment details (unclear risk of bias). Only two studies $(45,27)$ included adequate details of concealment of random allocation sequence. Some studies failed to report details pertaining to the blinding of key study participants and personal $(41.6 \%)(34,46,42,36,44)$. The majority of studies $(75 \%)$ provided evidence of attrition bias, reporting withdrawals from studies that may have led to incomplete outcome data, therefore studies accounted for this data being omitted. Irrespective of the study protocol available in each study, all individual studies clearly identified and reported pre-specified (primary and secondary) outcomes that aligned with the interests of this review (low risk of bias).

\section{Discussion}


This systematic review aimed to investigate the influence of professional learning models offered (length, mode and content) in physical activity interventions facilitated in early childhood education and care settings and children's objectively measured physical activity outcomes. Based on the quality of the evidence reviewed, the key components of successful physical activity centre-based interventions remain unclear. A number of key components, including professional learning for educators, have been suggested as potentially being important. However, in the studies included in this review there seemed to be inconsistent evidence on the length, mode and content of professional learning delivered to educators that is associated with changes in physical activity outcomes. Therefore, based on these included studies in this review, it is not possible to determine the influence that professional learning had on physical activity outcomes for children in early childhood education and care settings.

Studies included in this review varied considerably in sample size, length of intervention and focus of intervention. For example, some studies involved children from six child early childhood education and care settings while others involved children from 58 early childhood education and care settings and the intervention length ranged from six weeks to ten months. Some studies focused entirely on modifying physical activity levels (34) while others had a number of other outcomes. For example, Fitzgibbon et al intervention focused on physical activity, as well as television watching and nutrition (42) and Goldfield et al's, Jones et al's and Jones et al's interventions focused on physical activity and gross motor skill proficiency $(36,45,27)$. Bonvin et al's intervention strategy was different from all other studies in that they provided funds for the early childhood education and care settings to modify their indoor and outdoor environment to encourage the children to participate in more 
physical activity learning experiences (43). These study characteristics may have been more influential in physical activity changes rather than the knowledge gained through the professional learning sessions. Furthermore, given that most physical activity interventions are designed under a 'one size fits all" model (i.e. the same professional learning provided to all centres irrespective of the center's enrollment needs etc.), the lack of customization may also lead to further variability's in the effectiveness of physical activity based interventions (52).

Professional learning, within an early childhood education and care setting has traditionally been pivotal in initiating change within the sector based on the transference of knowledge. Thus, investigating the potential patterns between professional learning and physical activity outcomes was reasonable as one might hypothesise that the more professional learning received the greater the changes in physical activity. In the studies reviewed, professional learning may have contributed to the changes in physical activity; however, this is only speculative given very limited information provided in the studies that detailed the professional learning component of the interventions. On the whole information pertaining to the professional learning was scarce and/or poorly reported. The length and mode of delivery were briefly reported in most studies, however details regarding the content of the professional learning were limited for all studies. Studies typically provided general statements about the professional learning rather than detailing the specifics of the professional learning component. This is important particularly in studies that had multiple outcomes, for example Fitzgibbon et al's intervention assessed the feasibility and effectiveness of a teacher delivered weight control intervention covering topics around physical activity, nutrition and screen time (42). The 
professional learning component was mentioned however; specific content covered was not reported (42). Therefore, it remains unknown, how much of the professional learning was spent on each component (physical activity, television time and nutrition). If equal amount of time was spent on each component, this would mean that the face-to-face professional learning that focused on physical activity specifically was one hour in total, which is considerably less than the whole professional learning provided.

The seven studies that reported significant changes in physical activity outcomes all facilitated professional learning using traditional face-to-face sessions. Face-to-face professional learning usually involves one or two educators participating and then 'transferring' the information to other educators in their centre. In this review, only one study mentioned that 'all educators' received the professional learning (41), suggesting that in the other studies not all educators participated in the professional learning. Although this mode of professional learning remains popular within the early childhood education and care sector, it does have limitations. For example, on completion of the workshop, the attending educator/s are expected to transfer the 'new' information to other educators in their service, which generally results in limited transfer of knowledge. Other modes of professional learning, such as an online environment using synchronous and asynchronous platforms may be a viable option for professional learning within the early childhood education and care sector. Furthermore, given that such physical activity intervention require educators to attain new knowledge and to make ongoing changes to aspects of their everyday practices sustained professional learning over a longer period may be necessary $(53,54)$. 
Four of the eleven studies that reported significant changes in physical activity used a multi-component approach to professional learning $(43,42,36,27)$. It is plausible to suggest that professional learning models that implement face-to-face workshops in conjunction with other forms of professional learning (on site visits, additional meetings, refresher training opportunities) may promote positive changes in educators' practices and in turn lead to improvements in child physical activity outcomes. However additional evaluations of physical activity interventions are needed to confirm this.

For most of the studies an external professional facilitated the professional learning. This type of professional learning facilitation generally employs a 'top down' training model. In this model educators often feel that they are told what, when and how to make changes, with these suggestions being provided without consideration of the broader complex early childhood education and care environment. The 'top down' approach often results in limited ownership of the new knowledge $(55,56)$. Two studies did not use this approach: Goldfield et al used a 'train the trainer' model and in Jones et al's study the professional learning was delivered by an educator who had been seconded as the program champion for the intervention $(36,45)$. However, Goldfield et al reported significant differences between the intervention group and the control group in total physical activity and LPA, whilst Jones et al did not report any significant differences in physical activity outcomes (36). Although mixed results were reported in this review, facilitation of professional learning as part of physical activity in early childhood education and care interventions should be considered in future intervention. A recent study suggested that educators respond to professional learning that is facilitated by other educators who have been working in the sector for 
a number of years compared with professional learning facilitated by other professionals (57).

Although this review did not show identifiable influence patterns between the amount, type and duration of professional learning received and physical activity outcomes, it is clear the role of the educator in promoting physical activity experiences is essential (58). Educators determine children's daily routines, schedules and exposure to different learning experiences (59). Educators perceived benefits and barriers for different curricula areas could directly influence children's exposure to such learning experiences. For example, educators generally perceive children in early childhood education and care settings to be 'sufficiently active' and that their main role in relation to these learning experiences is a supervisory role (60). It's feasible to suggest that perhaps professional learning related to physical activity should not be specifically intervention focused but rather more general to re-shape the perceptions of educators regarding physical activity. Internationally, there is a dearth of such professional learning for educators. A recent study from Australia showed that $40 \%$ of educators across 200 child care settings had either never participated in professional learning for physical activity or had not done so in the past year. This illustrates that effective documentation of the role of educators is important in gaining a greater understanding of educators as agents of change in physical activity intervention outcomes (61).

It should also be noted that other external factors, including age, socio economic status, parental influences may affect physical activity of young children. Tonge et al., 2016 highlighted the older children (i.e. children aged 5 years were less active than 
young children (i.e. children aged 3 years) whilst attending early childhood education and care settings (62). Children from higher socio economic backgrounds have been shown to be more active than children from lower years in some studies $(63,64)$, however, in other studies the opposite has been reported. Also maternal physical activity has shown to influence young children's physical activity levels $(31,32,33)$. Ideally, these factors should be accounted for in analysis. Approximately half of the studies reported descriptive data relating to either ethnicity, socio economic status and parental education levels $(35,36,37,41,42,43,44,46)$. However, in this review no studies appeared to adjust for age, socio economic status, parental influences and thus may have influenced the outcomes of these studies.

\section{Strengths and Limitations}

This study followed the PRISMA statement (39), summarising the included studies in a reliable and accurate manner. Studies were assessed against the Cochrane Collaboration's assessment tool thereby assessing the quality and risk of bias of the primary studies. All studies reported objectively measured physical activity outcomes.

However, it is important to note the limitations of this review. All included studies in the review were limited to English. Second, whilst a comprehensive search across numerous databases with no date restrictions was used, it is possible that potential articles were overlooked due to the inclusion criteria used. Third, it was challenging when making comparisons between the studies given the inconsistent measures of physical activity and the variety of professional learning designs used. Furthermore, due to the small number of studies that met the inclusion criteria for this review, it was difficult to draw conclusions based on any potential patterns between professional learning in physical activity interventions facilitated in early childhood 
education and care settings and changes in children's objectively measured learning outcomes. Finally, given the included studies presented statistical evidence differently, a meta-analysis could not be performed, thus the lack of potential patterns was determined anecdotally.

\section{Conclusions}

In this review, potential patterns between the type, duration and frequency of professional learning for educators and physical activity outcomes was difficult to identify. The dearth of professional learning in the area of physical activity suggests that there is a need for such professional learning. Furthermore, professional learning is the key knowledge transfer mechanism in the early childhood education and care sector. However, the specific length, mode and content of professional learning offered as part of a physical activity intervention that potentially impacts on physical activity outcomes remain unresolved. Given the critical role of the educators in the early childhood education and care sectors the potential benefit of professional learning for educators, future studies could focus on more 'alternate' or 'multi-mode' professional learning designs (e.g. using a combination of face-to-face, on-site or online delivery) that are more content specific and contextually relevant to the needs of the educators. Future physical activity interventions for the early years, incorporating professional learning could also potentially consider learning that offers: opportunity for educators to reflect on their practices (i.e. reflective learning); support, guidance and mentoring from other educators or professionals which would provide a place for ongoing professional conversations the opportunity to be part of a professional community where educators could feel a sense of a belonging in a professional community. Such aspects have been suggested as key components of 
professional learning for early years educators' (65). Furthermore, given the very poor reporting of professional learning content and professional learning related outcomes (e.g. educator's self-efficacy, engagement and satisfaction) in this review there is ample scope for future studies to report on these components in a more comprehensive manner. Modifying young children's physical activity and in turn shaping children's health in the future is crucial and is influenced by a number of factors of which, if delivered correctly, could be professional learning. 


\section{References}

1. World Health Organization (2016)Report of the Commission on Ending Childhood Obesity Geneva: WHO; available at http://apps.who.int/iris/bitstream/10665/204176/1/9789241510066_eng.pdf

2. Weinsier, R. L., Hunter, G. R., Heini, A. F., Goran, M. I., \& Sell, S. M. (1998). The etiology of obesity: relative contribution of metabolic factors, diet, and physical activity. The American journal of medicine, 105(2), 145150.

3. Hinkley T, Teychenne M, Downing K et al. Early Childhood physical activity, sedentary behaviours and psychosocial well-being: A systematic review. Prev Med 2014; 62: 182-192.

4. Timmons B. W, LeBlanc A. G, Carson V et al. Systematic review of physical activity and health in the early years (aged 0-4 years). Appl Physiol Nutr Metab 2012; 37(4): 773-792.

5. Blake-Lamb, T. L., Locks, L. M., Perkins, M. E et al. (2016). Interventions for childhood obesity in the first 1,000 days a systematic review. American 
journal of preventive medicine, 50(6), 780-789.

6. Department of Health and Aging (DoHA). Move and play every day: national physical activity recommendations for children 0-5 years. Physical activity recommendations for 0-5 year olds, 2010;Commonwealth of Australia, Canberra.

7. Tremblay M. S, LeBlanc A. G, Carson V et al. Canadian physical activity guidelines for the early years (aged 0-4 years). Appl Physiol Nutr Metab 2012; 37(2): 345-356.

8. Department of Health. UK physical activity guidelines. Retrieved from http://www.dh.gov.uk/en/Publicationsandstatistics/Publications/PublicationsP olicyAndGuidance/DH_127931

9. Institute of Medicine (2011). Early childhood obesity prevention policies: goals, recommendations and potential actions. Institute of Medicine, 2011. http://www.nationalacademies.org/hmd/ /media/Files/Report\%20Files/2011/E arly-Childhood-Obesity-PreventionPolicies/Young\%20Child\%20Obesity\%202011\%20Recommendations.pdf

10. Tucker P. The physical activity levels of preschool-aged children: A systematic review. Early Childhood Research Quarterly 2008; 23(4): 547558.

11. Hinkley T, Salmon J, Okely A, Crawford D, Hesketh K. Preschoolers' Physical Activity, Screen Time, and Compliance with Recommendations. Med Sci Sports Exerc 2012; 44(3): 458-465.

12. National Academies of Sciences, Engineering, and Medicine. (2016). Obesity in the early childhood years: state of the science and implementation of promising solutions: workshop summary. National Academies Press. 
13. Botey A. P, Bayrampour H., Carson V., Vinturache A, Tough, S. Adherence to Canadian physical activity and sedentary behaviour guidelines among children 2 to 13years of age. Pre Med Rep 2006; 3: 14-20.

14. Kaphingst K. M, Story M. Child Care as an Untapped Setting for Obesity Prevention: State Child Care Licensing Regulations Related to Nutrition, Physical Activity, and Media Use for Preschool-Aged Children in the United States. Prev Chronic Dis 2009; 6(1): A11. https://www.ncbi.nlm.nih.gov/pmc/articles/PMC2644584/

15. Ling J, Robbins L, Wen F, Peng, W. Interventions to increase physical activity in children aged 2-5years: A systematic review. Pediatr Exerc Sci 2015; 27(3): 314-333.

16. Goldfield G. S, Harvey A, Grattan K, Adamo K. B. Physical activity promotion in the preschool years: a critical period to intervene. Int J Envir Res Pub Health 2012; 9(4): 1326-1342.

17. Ward D. S, Vaughn A, McWilliams C, Hales, D. Interventions for increasing physical activity at child care. Med Sci Sports and Exerc 2010; 42(3): 526534.

18. Temple M, Robinson J. C. A systematic review of interventions to promote physical activity in the preschool setting. J Spec Pediatr Nurs 2014; 19(4): 274-284.

19. Mahtala M, Saakslahti A, Inkinen M Poskiparta M. A structured socioecological approach to physical activity intervention in child care: a systematic review. Int J Behav Nutr Phys Act 2014; 11(2): 22

20. Hesketh K, Campbell, K. Interventions to prevent obesity in 0-5 year olds: An updated Systematic review of the literature. J Obes 2010; 18(1): 27-35. 
21. Puder J. J, Marques-Vidal P, Schindler C, et al. Effect of multidimensional lifestyle intervention on fitness and adiposity in predominantly migrant preschool children (Ballabeina): cluster randomised controlled trial. BMJ $2011 ; 343,6195$.

22. Zask A, Adamsa J.K, Brooks L, Hughes D.F. Tooty Fruity Vegie: an obesity prevention intervention evaluation in Australian preschools. Health Promot $J$ Austr 2012; 23(1): 10-15.

23. Morris H, Skouteris H, Edwards S, Rutherford L. Obesity prevention interventions in early childhood education and care settings with parental involvement: a systematic review. Early Child Dev Care 2015; 185(8): 12831313.

24. Adams J, Zask A, Dietrich U. Tooty Fruity Vegie in preschools: an obesity prevention intervention in preschools targeting children's movement skills and eating behaviours. Health Promot J Austr 2009; 20(2): 112-119. https://www.researchgate.net/publication/26705624_Tooty_Fruity_Vegie_in Preschools_An_obesity_prevention_intervention_in_preschools_targeting_chi $\underline{\text { ldren } \% 27 \mathrm{~s} \_ \text {movement_skills_and_eating_behaviours }}$

25. Bower JK, Hales DP, Tate DF, Rubin DA, Benjamin SE, Ward DS. A. The child care environment and children's physical activity. Am J Prev Med 2008; 34: $23-29$.

26. Broekhuizen K, Scholten A, De Vries S. The value of (pre)school playgrounds for children's physical activity level: a systematic review. Int J Behav Nutr Phys Act 2014; 11(1): 59. 
27. Jones R. A, Okely A. D, Hinkley T, Batterham M, Burke, C. Promoting gross motor skills and physical activity in childcare: A translational randomized controlled trial. J Sci Med Sport 2015; 19(9): 744-749.

28. Alhassan S, Nwaokelemeh O, Lyden K, Goldsby, T. and Mendoza, A. A Pilot Study to Examine the Effect of Additional Structured Outdoor Playtime on Preschoolers' Physical Activity Levels. Child Care Pract 2013; 19(1): 23-35.

29. Copeland K, Kendeigh C, Saelens B, Kalkwarf H, Sherman S. Physical activity in child-care centres: Do teachers hold the key to the playground? J Health Educ Res Dev 2012; 27(1): 81-100.

30. Androutsos O, Apostolidou E, Iotova V et al. Process evaluation design and tools used in a kindergarten-based, family-involved intervention to prevent obesity in early childhood. The ToyBox-study. Obes Rev 2014; 15: 74-80.

31. Oliver, M., Schofield, G. M., \& Schluter, P. J. (2010). Parent influences on preschoolers' objectively assessed physical activity. Journal of Science and Medicine in Sport, 13(4), 403-409.

32. Schoeppe, S., \& Trost, S. G. (2015). Maternal and paternal support for physical activity and healthy eating in preschool children: a cross-sectional study. BMC Public Health, 15(1), 971.

33. Sallis, J. F., Patterson, T. L., McKenzie, T. L., \& Nader, P. R. (1988). Family variables and physical activity in preschool children. Journal of Developmental and Behavioral Pediatrics.

34. Alhassan S, Nwaokelemeh O, Mendoza A et al. Feasibility and Effects of Short Activity Breaks for Increasing Preschool-Age Children's Physical Activity Levels. J Sch Health 2016; 86(7): 526-533. 
35. Pate R. R, Brown W. H, Pfeiffer K. A et al. An Intervention to increase physical activity in children: a randomized controlled trial with 4-year-olds in preschools. Am J Prev Med 2015; 51(1): 12-22.

36. Goldfield G. S, Harvey A. L, Grattan K. P et al. Effects of child care intervention on physical activity and body composition. Am J Prev Med, 2016; 51(2): 225-231.

37. Trost S. G, Fees B, Dzewaltowski D. Feasibility and efficacy of a "move and learn" physical activity curriculum in preschool children. J Phys Act Health, 2008; 5(1): 88-103.

38. Stanley R. M, Jones R. A, Cliff D. P, Trost S. G, Berthelsen D, Salmon J, Batterham M, Eckermann S, Reilly J, Brown N, Mickle K, Howard S, Hinkley T, Janssen X, Chandler P, Cross P, Gowers F, Okely A.D. Increasing physical activity among young children from disadvantaged communities: study protocol of a group randomised controlled effectiveness trial. BMC public health 2016; 16(1):1095.

39. Moher D, Liberati A, Tezlaff J, Altman D.G. Preferred reporting items for systematic reviews and meta-analysis; the PRISMA statement. J Inter Med 2009; 151 (4): 264-269.

40. Schardt C, Adams M. B, Owens T, Keitz S, Fontelo, P. Utilization of the PICO framework to improve searching PubMed for clinical questions. BMC Med Inform Decis Mak 2007; 7(1): 16.

41. Annesi J, Smith A, Tennant G. Effects of the Start for Life treatment on physical activity in primarily African American preschool children of ages 35 years. Psychol Health Med 2013; 18(3): 300-309. 
42. Fitzgibbon M.L, Stolley M,R, Schiffer L.A et al. Hip Hop to health Jr. obesity prevention effectiveness trial: Postintervention results. J Obes 2011; 19(5): 994-1003.

43. Bonvin A, Barral J, Kakebeeke T et al. Effect of a governmentally-led physical activity program on motor skills in young children attending child care centres: a cluster randomized trial. Int J Behav Nutr Phys Act. 2013; 10(1): 90-102.

44. O’Dwyer M. V, Fairclough S.J, Ridgers N.D et al. Effect of a school-based active play intervention on sedentary time and physical activity in preschool children. J Health Educ Res Dev 2013; 28(6): 931-942.

45. Jones R, Hesketh K, Trezise J, Batterham M, Okely A.D. Promoting fundamental movement skill development and physical activity in early childhood settings: a cluster randomized controlled trial. Pediatr Exerc Sci 2011; 23(4): 600-615.

46. De Marco A. C, Zeisel S, Odom S.L. An evaluation of a program to increase physical activity for young children in Child Care. Early Educ Dev 2015; 26(1): 1-21.

47. Pate R. R, Almeida M. J, McIver K. L, Pfeiffer K. A, Dowda M. Validation and calibration of an accelerometer in preschool children. J Obes 2006, 14(11): 2000-2006.

48. Sirard J. R, Trost S. G, Pfeiffer K. A, Dowda M, Pate R. R. Calibration and evaluation of an objective measure of physical activity in preschool children. $J$ Phys Act Health 2005; 2(3): 345-357. 
49. Adolph A. L, Puyau M. R, Vohra F. A et al. Validation of uniaxial and triaxial accelerometers for the assessment of physical activity in preschool children. $J$ Phys Act Health 2012; 9(7): 944-953.

50. Pfeiffer K. A, Mciver K. L, Dowda M, Almeida M. J, Pate R. R. Validation and calibration of the Actical accelerometer in preschool children. Med Sci Sports Exerc 2006; 38(1): 152-157.

51. Pate R. R, Pfeiffer K. A, Trost S. G, Ziegler P, Dowda M. Physical activity among children attending preschools. Pediatrics 2004; 114(5): 1258-1263.

52. Howie E, Brewer A, Brown W, Pfeiffer K, Saunders R et al. The 3-year evolution of a preschool physical activity intervention through a collaborative partnership between research interventionists and preschool teachers. $J$ Health Educ Res Dev 2014; 29(3): 491-502.

53. Patton K \& Parker M. I learned more at Lunchtime: Guideposts for reimaging Professional Development. J Phys Educ Rec Danc 2015; 86(1): 23-29.

54. Hadley F, Waniganayake M, Shepherd W. Contemporary practice in professional learning and development of early childhood educators in Australia: reflections on what works and why. J Prof Dev Educ 2015; 41(2): 187-202.

55. Olofsson D. Discussions in online learning community forums- do they facilitate teachers' professional development? The University of Fraser Valley research review 2010; 3(2): 54-68. http://journals.ufv.ca/rr/RR32/articlePDFs/5-olofsson.pdf

56. Marklund L. Preschool teachers' informal online professional development in relation to educational use of tablets in Swedish preschools. J Prof Dev Educ 2015; 42(2): 236-253. Aust J Early Child 2017; 42(1): 81-84. 
57. Jones R, Gowers F, Stanley R, Okely A.D. Enhancing the effectiveness of early childhood educators and researchers working together to achieve common aims.

58. Tonge K. L, Jones R. A, Okely, A. D. Correlates of children's objectively measured physical activity and sedentary behaviors in early childhood education and care services: A systematic review. Prev Med 2016; 89: 129139.

59. Bell J, Hamer M, Hees V et al. Health Obesity and objective physical activity. Am J Clin Nutr 2015; 102(2): 268-275.

60. Dyment J \& Coleman B. The intersection of physical activity opportunities and the role of early childhood educators during outdoor play: Perceptions and reality. Aust J Early Child 2012; 37(1): 90-98.

<http://search.informit.com.au/documentSummary;dn=216933293592974;res $=$ IELHSS $>$ ISSN: $1836-9391$

61. Lander N, Eather N, Morgan P, Salmon J, Barnett L. Characteristics of Teacher Training in School-Based Physical Education Interventions to Improve Fundamental Movement Skills and/or Physical Activity: A Systematic Review. Sports Med 2017; 47(1): 135-161.

62. Tonge, K. L., Jones, R. A., \& Okely, A. D. (2016). Correlates of children's objectively measured physical activity and sedentary behavior in early childhood education and care services: a systematic review. Preventive medicine, 89, 129-139.

63. Duncan, M. J., Birch, S., Al-Nakeeb, Y., \& Nevill, A. M. (2012). Ambulatory physical activity levels of white and South Asian children in Central England. Acta Paediatrica, 101(4). 
64. Drenowatz, C., Eisenmann, J. C., Pfeiffer, K. A et al. (2010). Influence of socio-economic status on habitual physical activity and sedentary behavior in 8-to 11-year old children. BMC public health, 10(1), 214.

65. Cherrington S, Thornton K. Continuing professional development in early childhood education in New Zealand. Early Years: Inter Res J 2012; 33(2): 119-132. 
